\title{
Hospital Pharmacy in Canada: Ahead of the Curve
}

\author{
James E Tisdale and Kevin W Hall
}

$\mathrm{I}^{\mathrm{n}}$

n 2008, the American Society of Health-System Pharmacists (ASHP) and its Research and Education Foundation initiated the Pharmacy Practice Model Initiative (PPMI), the goal of which is to "significantly advance the health and well-being of patients in hospitals and health systems by developing and disseminating optimal pharmacy practice models that are based on the effective use of pharmacists as direct patient care providers." Some of the primary objectives of the PPMI for hospitals and health systems are to describe optimal pharmacy practice models that support the provision of safe, effective, efficient, and accountable medication-related care for patients; to enhance the capacity of pharmacy technicians; to identify core patient-care-related services that should be consistently provided by departments of pharmacy; to foster understanding of and support for optimal pharmacy practice models by patients and caregivers, health care professionals, health care executives, and payers; to identify existing and future technologies required to support optimal pharmacy practice models; and to identify specific actions that hospital pharmacists should take to implement optimal practice models.

In November 2010, ASHP held an invitational conference, the Pharmacy Practice Model Summit, at which over 100 pharmacy leaders met to reach consensus on the types of pharmacy practice models that would best serve the needs of both patients and the hospitals and health systems that deliver care to those patients. The consensus recommendations from the summit are numerous, but the following are some of the more noteworthy ${ }^{2}$ :

- Hospital and health-system pharmacists must be responsible and accountable for patients' medication-related outcomes.

- Drug therapy management should be provided by a pharmacist for each hospital inpatient.

- Through credentialling and privileging processes, pharmacists should include in their scope of practice prescribing as part of the collaborative practice team.

- All distributive functions that do not require clinical judgment should be assigned to technicians.

- $\quad$ Pharmacists providing drug therapy management should
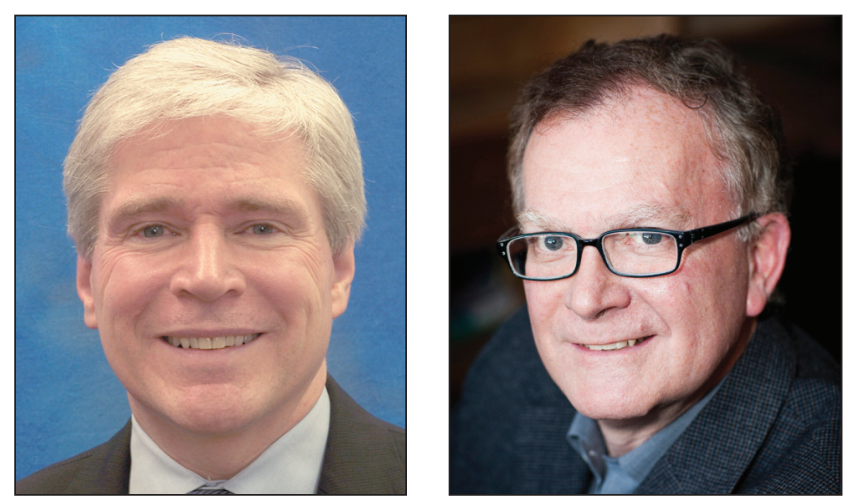

have completed an accredited residency program or have equivalent experience.

- Pharmacists who provide drug therapy management should be certified through the most appropriate Board of Pharmacy Specialties certification process.

The Pharmacy Practice Model Summit did not result in specific recommendations for one or more distinct practice models, but rather led to calls for "bold actions that will propel health-system pharmacy into the future", ${ }^{3}$ with an emphasis on "the imperative for pharmacy departments to reform their deployment of pharmacist, technician, and technology resources." "The Summit's proceedings included examples of what were referred to as "cutting-edge practice models". The example of a "cutting-edge" practice model provided for a small community hospital was the deployment of a pharmacist to participate on a collaborative health care team that also includes a physician, nurse, and care manager. ${ }^{5}$ However, such models have been in place at many institutions for decades, and it could be argued that describing such practices as "cutting-edge" sets the bar very low. The example of a "cutting-edge" practice model for a large academic medical centre was a decentralized model in which undefined "clinical staff or specialists" were deployed, along with decentralized pharmacy technicians, to multiple patient care areas, with the goal of minimizing pharmacists' nonclinical work through the expanded use of technology and pharmacy technicians. ${ }^{6}$ Although these strategies are important, 
they are neither new nor particularly innovative- the expanded use of technicians and technology has been advocated by leaders in the profession since the early 1960s. ${ }^{7.8}$

We count ourselves among those who believe that the PPMI in the United States has been too timid in its advocacy for cutting-edge pharmacy practice models. Some recent developments in Canada suggest that Canadian pharmacy practice is well positioned to achieve transformational change in hospital pharmacy practice that would raise the bar above that set by ASHP's PPMI.

To begin with, regulation and certification of pharmacy technicians, already established in several Canadian provinces and well under way in most others, create the opportunity for regulated pharmacy technicians to assume responsibility and accountability for the technical aspects of drug distribution. Although some hospital pharmacy departments continue to believe that pharmacists must maintain a major role in the drug distribution system, many others have adopted, or are pursuing, practice models in which the goal is a technician-managed, technology-assisted drug distribution system that frees pharmacists to focus their efforts almost exclusively on working with patients to optimize drug therapy outcomes. ${ }^{9}$ Without regulation and certification of pharmacy technicians, the pharmacist's ultimate responsibility for the drug distribution system has been both a perceived and a real barrier to freeing pharmacists from technical drug distribution activities. Throughout Canada, that barrier is now falling as regulation of pharmacy technicians rapidly rolls out across the country.

The pharmacist's ability to manage drug therapy has also been challenged by a lack of prescribing authority, but that barrier to cutting-edge pharmacy practice models is also falling. Alberta led the way in granting independent prescriptive authority to pharmacists, ${ }^{10}$ and most other provincial jurisdictions have pursued or are pursuing similar regulatory changes that will give pharmacists a level of prescriptive authority enabling them to assume greater responsibility and accountability for drug therapy management.

Canadian hospital pharmacy practice has certainly not yet achieved all of the recommendations arising from the Pharmacy Practice Model Summit. Residency capacity is a serious issue in Canada as well as in the United States, and it will likely be some time before all Canadian pharmacists who provide drug therapy management will have completed an accredited residency program. In addition, although 163 Canadian pharmacists had Board of Pharmacy Specialties certification as of mid-2012 (according to the Board's database of certified pharmacists, at www.bpsweb.org/resources/find_bcp.cfm), such certification has not yet found widespread acceptance in Canada. Leaders in Canadian hospital pharmacy practice will have to decide if there is value in credentialling and privileging and whether board certification should play a role.

There is much work to be done to identify optimal institutional pharmacy practice models, including conducting comparative effectiveness research to determine which specific models lead to the best patient care outcomes. Nonetheless, pharmacy departments in Canadian hospitals continue to innovate in terms of their practice models, have much to be proud of, and are definitely ahead of the curve.

\section{References}

1. American Society of Health-System Pharmacists. Pharmacy Practice Model Summit. Executive summary. Am J Health Syst Pharm 2011;68(12): 1079-1085.

2. The consensus of the Pharmacy Practice Model Summit. Am J Health Syst Pharm 2011;68(12):1148-1152.

3. Zellmer WA. Reflections on the key messages of the Pharmacy Practice Model Summit. Am J Health Syst Pharm 2011;68(12):1153-1154.

4. Zellmer WA, Cobaugh DJ, Chen D. Three signals from the Pharmacy Practice Model Summit [editorial]. Am J Health Syst Pharm 2011;68(12):1077.

5. Berry R. Cutting-edge practice model: experience in a small community hospital. Am J Health Syst Pharm 2011;68(12):1113.

6. Mason KC. Cutting-edge practice model: an integrated model within a large academic medical center. Am J Health Syst Pharm 2011;68(12):1112.

7. Sonnedecker G. Kremers and Urdang's history of pharmacy. 4th ed. Madison (WI): American Institute of the History of Pharmacy; 1976. p. 241.

8. Francke DE. Prescription for pharmacy practice 1984. Drug Intell Clin Pharm 1976;10(2):111-112.

9. Hall KW, Raymond CB, Woloschuk DMM, Honcharik N. Organizational restructuring of regional pharmacy services to enable a new pharmacy practice model. Can J Hosp Pharm 2011;64(6):451-456.

10. Yuksel N, Eberhart G, Bungard TJ. Prescribing by pharmacists in Alberta. Am J Health Syst Pharm 2008;65(22):2126-2132.

James E Tisdale, BScPharm, PharmD, is Professor and Interim Head, Department of Pharmacy Practice, College of Pharmacy, Purdue University, and Adjunct Professor, School of Medicine, Indiana University, Indianapolis, Indiana. He is also an Associate Editor for the CJHP.

Kevin W Hall, BScPharm, PharmD, is a Clinical Associate Professor with the Faculty of Pharmacy and Pharmaceutical Sciences, University of Alberta, Edmonton, Alberta. He is also an Associate Editor for the CJHP.

\section{Address correspondence to:}

Dr James E Tisdale

Department of Pharmacy Practice

College of Pharmacy

Purdue University

W7555 Myers Building, WHS

1001 West 10th Street

Indianapolis IN 46202 USA

e-mail: jtisdale@purdue.edu

Dr Kevin W Hall

Faculty of Pharmacy and Pharmaceutical Sciences

ECHA 3-228

University of Alberta

Edmonton AB T6G 1 C9

e-mail: khall@pharmacy.ualberta.ca 